\title{
Michel BIARD et Philippe BOURDIN (dir.), Robespierre.
}

Portraits croisés

Paris, Armand Colin, 2013

\section{Jean-Clément Martin}

\section{(2) OpenEdition Journals}

Édition électronique

URL : https://journals.openedition.org/ahrf/13113

DOI : 10.4000/ahrf.13113

ISSN : 1952-403X

Éditeur :

Armand Colin, Société des études robespierristes

Édition imprimée

Date de publication : 1 mars 2014

Pagination : 230-231

ISBN : 978-2-200-9083-2790-8

ISSN : 0003-4436

Référence électronique

Jean-Clément Martin, "Michel bIARD et Philippe bourdin (dir.), Robespierre. Portraits croisés ", Annales historiques de la Révolution française [En ligne], 375 I janvier-mars 2014, mis en ligne le 08 juillet 2014, consulté le 05 juillet 2021. URL : http://journals.openedition.org/ahrf/13113 ; DOI : https://doi.org/ 10.4000/ahrf.13113

Ce document a été généré automatiquement le 5 juillet 2021.

Tous droits réservés 


\section{Michel BIARD et Philippe BOURDIN (dir.), Robespierre. Portraits croisés}

Paris, Armand Colin, 2013

Jean-Clément Martin

\section{RÉFÉRENCE}

Michel BIARD et Philippe BOURDIN (dir.), Robespierre. Portraits croisés. Paris, Armand Colin, 2013, 288 p., ISBN 978-2-200-27771-0, 24,50€.

1 Robespierre est plus que jamais d'actualité. Après l'achat des manuscrits de Robespierre et de Lebas par les Archives nationales, soutenu par la souscription lancée par la Société des études robespierristes, le numéro des Annales historiques de la Révolution française et la biographie publiée par Peter McPhee, ce volume illustre l'attention et le renouvellement des études consacrées à Robespierre. Son propos affirmé est de ne pas se contenter de ce qui est su et répété depuis des années, mais il entend rouvrir les dossiers et reprendre les sources originales. Les dix-sept auteurs des quinze contributions composent un ensemble qui n'épuise certes pas les questions posées dans l'introduction signée par les deux directeurs à propos de l'énigme que Robespierre représente à maints égards, mais ils proposent des points de vue très variés.

2 Si la difficulté est toujours grande pour rendre compte d'un livre collectif, la tâche est compliquée par la diversité des thèmes et des méthodes. L'attention érudite pourrait être le fil rouge du livre. Tous les auteurs s'attachent à prendre le contrepied des approximations courantes avec un luxe de précautions, ce qu'illustrent par exemple les deux articles d'ouverture, celui d'Hervé Leuwers exposant précisément les affaires judiciaires dans lesquelles Robespierre s'est impliqué, et celui de Claude Mazauric démêlant l'attribution d'une " dédicace » aux mânes de Jean-Jacques Rousseau publiée dans une édition des mémoires de Robespierre en 1830. La volonté d'éclairer par la biographie les options politiques est elle aussi une constante, qui est particulièrement 
présente dans l'article de Peter McPhee enracinant les décisions autour de la famille dans les souvenirs d'enfance de Maximilien Robespierre, comme dans celui de JeanPierre Gross insistant sur l'activité de l'avocat défenseur des pauvres pour comprendre toute la politique suivie après 1789 - enracinement expliquant aussi les limites de la pensée.

3 Pratiquement toutes les contributions s'attachent à résoudre une contradiction imputée à Robespierre. Jean-Pierre Gross sort de l'aporie relevée entre les intentions de Robespierre et son incapacité à régler les conflits entre respect de la propriété et droits des plus pauvres en montrant "le grain de folie » de Robespierre voulant rénover le monde par l'introduction de valeurs morales républicaines. Jean-Pierre Jessenne développe une problématique proche pour parler de la politique sociale de Robespierre, qui aurait été sujette à des « modulations » en lien avec les contraintes politiques. Jean Bart s'attaque à la présentation ordinaire de Robespierre désireux d'abolir la peine de mort mais réclamant la tête du roi au nom de la sûreté de l'État. Bernard Gainot montre que l'intérêt porté par Robespierre à la question coloniale aura connu des éclipses et aura suivi finalement l'opinion de son temps. Marc Belissa s'emploie à conjuguer les prises de position contre la guerre de conquête et l'armée avec le besoin de mener des guerres défensives au profit de la liberté. Philippe Bourdin expose les conditions dans lesquelles Robespierre présente le projet éducatif de Lepeletier de Saint-Fargeau, alors qu'il n'est pas beaucoup intervenu dans ce champ.

4 Ces lignes directrices se remarquent dans les articles qui suivent, mais ceux-ci portent des innovations plus marquées dans ce champ de recherches. C'est le cas de Paul Chopelin s'attaquant au mythe de Robespierre « grand prêtre » et suivant précisément l'évolution de ses positions sur la religion, expliquant finement l'invention d'un messianisme vertueux contre les fanatismes des prêtres et des déchristianisateurs. En utilisant, lui aussi, les dénonciations portées contre Robespierre, Pierre Serna peint ce dernier comme un grand tacticien porteur d'un projet politique quasi irréalisable. A-t-il comme l'auteur le dit, "incarné [les] deux facettes de la politique moderne »? Les exemples cités mériteraient d'être élargis à d'autres acteurs, comme Saint-Just ou Billaud-Varenne, sans doute proches à maints égards de la posture de Robespierre. C'est précisément en suivant cette inclusion dans le groupe des membres des Comités que Guillaume Mazeau récuse l'idée que Robespierre ait été un dictateur et fait comprendre comment il l'est devenu aux yeux de l'opinion manipulée. L'isolement du personnage explique alors qu'il soit devenu « l'incarnation » de la Révolution.

5 Ce sont les retombées de ces dénonciations que suivent Michel Biard, de 1794 à 2009 pour illustrer «la double mort de Robespierre", Annie Duprat et Laurent Bihl exploitent les portraits réalisés dès 1789 jusque dans les années 1980 pour conclure à l'incapacité de répondre à la question de savoir qui était Robespierre. L'incapacité à répondre à Marc Bloch est démontrée par Jean-Numa Ducange et Pascal Dupuy s'interrogeant sur l'historiographie depuis l'immédiat après Thermidor jusqu'à nos jours. En suivant les débats bien connus, ils recensent les silences et les polémiques qui scandent notre connaissance jamais consensuelle de Robespierre. Au final, en refermant le livre, les voies les plus fécondes semblent bien être celles qui ont su lier les épaisseurs historiographiques aux connaissances érudites, assurant la progression des connaissances par la discussion avec les courants antérieurs et les opinions les plus diverses. Si le titre de l'ouvrage, portraits croisés, se justifie le mieux c'est sûrement 
dans cette dimension qui prend en compte les traditions et les approximations, qui ont toujours été aux fondements de la recherche historique. 